\title{
Thomas Kuhn e a nova historiografia da ciência
}

\author{
Bernardo Jefferson de Oliveira - Fae/UFMG \\ Mauro Lúcio Leitão Condé - Fafich/UFMG
}

\section{Resumo:}

Esse artigo procura mostrar a crítica de Thomas Kuhn a algumas concepções da historiografia da ciência contemporânea que radicalizaram muitas das posições formuladas inicialmente pelo próprio Kuhn. Pretende-se ainda mostrar que um reposicionamento de Kuhn, a partir de sua crítica a seus sucessores, o aproxima mais de suas influências iniciais, em especial, de Ludwig Wittgenstein e Ludwik Fleck.

Palavras-chave: historiografia da ciência, conhecimento científico, Thomas Kuhn

\section{Abstract:}

This article tries to show the Thomas Kunn's critics to some conceptions of the contemporary historiography of science that became radical many of the positions formulated initially by Kuhn himself. It is still intended to show that the new orientation of Kuhn, starting from his critic to his successors, approaches him more of his initial influences, especially, Ludwig Wittgenstein and Ludwik Fleck.

key-words: science historiography, scientific knowledge, Thomas Kuhn

Lewis Carroll, celebre por seu livro Alice no país das maravilhas, adorava brincar com paradoxos. No poema Caça ao turpente, ele se diverte, entre outras coisas, com os fundamentos do conhecimento. Há uma passagem bastante sugestiva sobre a idéia de que a ciência e suas descobertas não passam de meras convenções. Nela lemos que o capitão do barco que lidera a caçada

\section{Comprara amplo mapa mostrando o mar}

\section{Sem o mínimo sinal de terra:}

A tripulação gritou vivas ao ar:

"Com um mapa assim ninguém erra!"

"Pra que serve o equador do Sr. Mercator, Seus trópicos , pólos, monções?"

Perguntava o do sino. ${ }^{1}$ A resposta, com tino:

"São meras pueris convenções!

Feios feito quiabos, com ilhas e cabos,

\footnotetext{
${ }^{1} \mathrm{O}$ capitão se chamava Bellman. Na excelente tradução de Álvaro Antunes que estamos utilizando, ele é o Campainha.
} 
Esses mapas nos dão calafrio,

Campainha é o maior, nos comprou o melhor:

Um completamente vazio!"

Podemos rir da utilidade de um mapa onde não se representa nada senão água, mas fica no ar a suspeita de que as representações que retratam a realidade, ainda que possam ter grande serventia, não passam de "invencionices".

Mas será a ciência uma construção social como qualquer outra manifestação cultural? Não teria a natureza um papel fundamental em impor resistência às falsas representações (hipóteses, teorias, e usos) que fazemos dela? Nesse caso, nossas representações não dependeriam menos dos acertos sociais do que das lições que tiramos das experiências que fazemos com a natureza para aferir nossas idéias e expectativas?

A consideração do conhecimento científico como mera representação social provocou o que ficou conhecido como a "guerra das ciências": uma disputa acirrada entre aqueles que relativizam a autoridade da ciência como conhecimento acerca da natureza e aqueles que reagem desqualificando tais estudos. Via de regra, a reação vinha da parte dos representantes das ciências naturais e, ao passo que os estudos críticos se apoiavam, em sua maioria, nas discussões contemporâneas (virada lingüística, pragmatismo, desconstrutivismo etc.) das ciências humanas.

Entre historiadores da ciência, vem se difundindo cada vez mais a perspectiva de não considerar o desenvolvimento das ciências tão somente a partir das seqüências de teorizações, experimentos e argumentações, mas de buscar enriquecer a compreensão do fenômeno científico a partir das práticas científicas e dos mecanismos sociais de negociação e legitimação que envolvem a produção, a aceitação e a difusão dessas práticas.

Thomas Kuhn é tido como um divisor de águas na história das ciências. Sua noção de paradigma como algo que circunscreve o que o cientista observa e problematiza, e a consideração de que diferentes paradigmas científicos são incomparáveis ("incomensuráveis") teria fomentado uma abordagem sócioconstrutivista das ciências, que procura compreender a prática e o desenvolvimento científico como equivalente ao de qualquer outra instituição social, isto é, como fruto de negociações e acordos entre grupos. Dessa forma, em vez da comparação analítica das teorias, que visa à análise da coerência, ou de sua abrangência e alcance, procura-se entender o sucesso das explicações científicas como vinculado à trama social, política e institucional na qual tais explicações são produzidas, mantidas e alteradas.

Todavia, Kuhn não concordava com boa parte dessas idéias e viveu os últimos anos de sua vida desconcertado com a imagem que o havia tornado mundialmente conhecido. Kuhn morreu em 1996 e acompanhava, recatada mas atentamente, o que na época se discutia em filosofia, sociologia e em historiografia da ciência. Estava há alguns anos trabalhando num livro que ficou inacabado, The plurality of worlds: An evolutionary theory of scientific discovery. Entretanto, ia externado as direções de seu novo trabalho em prefácios a estudos sobre sua obra, posfácios a reedições de seus livros, conferências, entrevistas e artigos que apresentava em congressos. Uma seleção desses trabalhos foi publicada em 
2000 com o título The road since Structure. Nessa coletânea, a posição de Kuhn frente a essa tendência sócioconstrutivista aparece com maior destaque em três escritos: "The road since structure", que emprestou o nome ao livro, foi uma conferência proferida no encontro da Associação americana de Filosofia da Ciência (PSA) de 1990; "Afterwords", que é um comentário de Kuhn aos trabalhos apresentados num colóquio em sua homenagem no MIT em 1990, e posteriormente editado por Paul Horwich; "The trouble with the historical philosophy of Science", ${ }^{2}$ uma conferência feita na Universidade de Harvard em 1991; e "A discussion with Thomas Kuhn" que é a transcrição de uma longa entrevista concedida em Atenas, em 1995. Em todos estes escritos, Kuhn se refere, com alguma aflição, aos desdobramentos ou extensões que suas idéias teriam gerado. De certa forma, um desconforto com sua própria produção, que, no mínimo, tinha dado margem a interpretações equivocadas e que necessitava, portanto, de revisões. Tais revisões são elucidativas pois especificam, nas interpretações possíveis, o sentido desejado.

Kuhn tenta então reavaliar algumas de suas formulações iniciais e se desvencilhar da tendência sócioconstrutivista nos estudos sobre a ciência. Dentro dessa tendência há, sem dúvida, diferenças importantes e com notáveis implicações. No entanto, grosso modo, as tendências sócio-construtivistas concordam com a idéia de que não há um "substrato natural", um fundamento empírico ou uma realidade a ser buscada, e que, portanto, a ciência é uma construção social. Assim, ao invés de tentar, por exemplo, refazer experiências, reconstruir instrumentos ou examinar as implicações conceituais e lógicas de argumentos, os historiadores da ciência passaram a privilegiar em suas análises as práticas de negociação do estabelecimento de consensos e difusão das interpretações das científicas.

Antes de vermos em que se diferenciava a posição de Kuhn, vejamos traços e inclinações comuns. Uma tendência convergente, que é reconhecida como uma das contribuições da obra de Kuhn, é a contestação da autoridade que os fatos científicos e o papel que a argumentação racional tinham na história da ciência. Essa perspectiva foi, na época e durante um bom tempo, vista como sendo relativista. Mas não eram só os críticos, e dentre eles Popper, que viam o viés de Kuhn como relativista. O próprio Kuhn o assumia em parte.

Os defensores de teorias diferentes são como membros de comunidades de cultura e linguagem diferentes. Reconhecer esse paralelismo sugere, em certo sentido, que ambos os grupos podem estar certos. Essa posição é relativista, quando aplicada à cultura e seu desenvolvimento. Mas quando aplicada à ciência, ela pode não sê-lo e, de qualquer modo, está longe de um simples relativismo, num aspecto que meus críticos não foram capazes de perceber (Kuhn, 1978, 251).

Kuhn justifica essa direção em parte vinculando-a ao movimento geral de contestação da autoridade, no final dos anos 60. A descrença de que a autoridade de uma razão científica, fazia perceber as reconstruções históricas como excessivamente racionalistas, 0 que implicava em buscar novas explicações para o processo pelo qual diferenças de crença eram reconciliadas e convergiam para um consenso final no grupo. Assim, o que se tornou marcante com sua obra foi a investigação do processo no qual o resultado dos experimentos

\footnotetext{
${ }^{2}$ A tradução desse texto se encontra disponível no site www. fafich.ufmg.br/ scientia
} 
é especificado como um fato, em cima do qual se baseia a autoridade de novas crenças, novas leis e teorias científicas.

Essas eram as questões centrais para o trabalho da geração que seguiu a minha, e a principal contribuição de que se valeram veio não da filosofia, mas do novo tipo de estudos históricos, mais especificamente sociológicos, que o trabalho de minha geração ajudou a criar. Esses estudos trataram, em detalhes microscópicos, dos processos internos de uma comunidade científica ou grupo no qual um consenso finalmente ganha autoridade. Processo esse que é freqüentemente tratado por essa literatura como "negociação"(Kuhn, 2000, 109).

Passou-se, então, a tentar conhecer o processo de estabelecimento dos fatos científicos, de como se negociava a aceitação destes e das teorias que neles se fundavam. O que esta abordagem revelava era que esses dois aspectos da negociação - o factual e o interpretativo - eram simultâneos e circulares: as conclusões dando forma às descrições dos fatos, e estes constituindo as conclusões tiradas deles. A circulariedade evidenciada mostrava, entre outras coisas, como era frágil o peso que se dava aos experimentos na determinação de seus resultados e como as interpretações e conclusões científicas dependem de contingências e de fatores não racionais.

Mas como um processo tão circular e tão dependente de contingências individuais poderia vir a resultar seja em uma verdade ou seja em conclusões prováveis acerca da natureza da realidade? Esta é uma questão séria e considero que a inabilidade em responde-la é uma falta grave em nossa compreensão sobre a natureza do conhecimento científico. Mas a questão emergiu durante os anos 60, quando estava disseminada a desconfiança em relação a todos os tipos de autoridade, e se estava a um pequeno passo de ver a falta de autoridade como um ganho. Se dizia, especialmente entre sociólogos e cientistas políticos, que as negociações em ciência, assim como aquelas em política, diplomacia, comércio e muitos outros aspectos da vida social, eram governadas pelo interesse, e seus resultados determinados por considerações de autoridade e poder. Esta era a tese daqueles que começaram a empregar o termo "negociação" ao processo científico, e o termo carregava muito da tese com ele (Kuhn, 2000, 110).

Kuhn não julgava que o termo nem a descrição das atividades que ele cobria fossem meramente equivocados. "Interesse, políticas, poder e autoridade desempenham indubitavelmente um papel significante na vida científica e em seu desenvolvimento." Entretanto, a ênfase nesses aspectos tornava difícil de ver o que mais desempenharia algum papel na ciência.

Chegamos, então, na contraposição de Kuhn a seus descendentes, que poderia talvez ser resumida no seguinte: a prioridade ou exclusividade que a historiografia da ciência passa a dar às questões de poder e interesse.

A própria natureza, seja lá o que ela for, parece não ter parte alguma no desenvolvimento de crenças a seu respeito. Conversa sobre evidências, da racionalidade de asserções delas tiradas, da verdade ou probabilidade dessas 
asserções têm sido vistas meramente como retórica, atrás da qual o partido vitorioso disfarça seu poder. $O$ conhecimento científico, então, não passa da simples crença dos vencedores.

Eu estou entre aqueles que acharam absurdas as proposições do programa forte: ${ }^{3}$ um exemplo da desconstrução enlouquecida. E as formulações mais qualificadas sociológica e historicamente que, atualmente, se esforçam por substituí-las satisfazem, a meu ver, muito pouco. Essas formulações mais novas reconhecem, sem constrangimentos, que observações da natureza desempenham sim um papel no desenvolvimento científico. Mas elas permanecem quase totalmente vagas sobre qual o seu papel, de qual maneira a natureza entra na negociação que produz crenças a seu respeito (ibidem, 110).

Decerto, Kuhn considera muitos desses estudos brilhantes e reveladores de aspectos desconhecidos do processo científico, mas que, entretanto, descuidam de importantes aspectos técnicos. Um exemplo ilustrativo é o do livro Levitã e a bomba de ar (Shapin \& Shaffer, 1985), que chegou a ser apontado como um divisor de águas na historiografia da ciência. Embora Kuhn achasse esse livro interessante sobre vários aspectos, ele ficou impressionado com o desconhecimento ou descaso de seus autores com alguns dos pressupostos e conceitos teóricos com que Boyle tratava a pressão do ar. Vejamos o caso mais de perto. Shapin e Shaffer observam que Boyle trata às vezes sobre pressão e noutras sobre a mola do ar, e, vendo inconsistência nessa alternância, fazem dela um exemplo de como o debate com Hobbes era de certa forma vazio, ou seja, mais retórico que substancial. Kuhn considera que se os autores levassem em conta que, ao tratar do ar, Boyle usava o modelo hidrostático, eles teriam visto que aquela alternância no tratamento da questão não tinha nada de incompatível nem de inconsistente. Portanto, resgatando aqui o valor de uma análise internalista mais atenta aos detalhes técnicos das teorias e experimentos, Kuhn advoga a importância de "motivos racionais" dentro daquela perspectiva adotada pelo químico inglês. Casos como esse são, a seu ver, geralmente consideradas sem importância pelos estudantes da nova historiografia da ciência (Kuhn, 2000, 316). Por isso, Kuhn ressalva que o termo "negociação" é em muitos casos correto apenas se pensado como uma metáfora, ainda que seja literal em alguns outros.

Para ele, o principal problema estava no papel secundário que a natureza ocupa em tais estudos.

Sua novidade e sua importância não podem, penso eu, ser questionadas. Mas sua rede de efeitos, ao menos de uma perspectiva filosófica, tem sido a de aprofundar, mais do que eliminar, a própria dificuldade que estava-se buscando resolver (Kuhn, 2000, 109).

\footnotetext{
${ }^{3}$ Programa Forte aqui é o Programa Forte de Sociologia da Ciência de D. Bloor e B. Barnes que procura mostrar a radicalidade da dimensão sociológica envolvida na produção do conhecimento científico. Em outras palavras, para esses autores, os aspectos sociais não são apenas complementares na produção da ciência, mas determinantes (Cf. BLOOR, 1976).
} 
Entretanto, Kuhn não se contenta em apontar falhas ou descartar tais perspectivas, mas buscar entender os dilemas que colocavam.

O programa forte e seus descendentes têm sido repetidamente descartados como expressões descontroladas de hostilidade à autoridade em geral e, em particular, à científica. Eu mesmo reagi dessa maneira por alguns anos. Mas agora eu penso que essa fácil avaliação ignora um real desafio filosófico. Existe uma linha de continuidade entre a inescapável observação inicial que subjaz os estudos microsociológicos e suas conclusões, ainda inteiramente inaceitáveis. Muito do que não deve ser abandonado foi aprendido no percurso dessa linha. Mas ainda não está claro como, sem abandonar essas lições, a linha pode ser desviada ou interrompida, ou como se pode evitar suas conclusões inaceitáveis (Kuhn, 2000, 111).

Enfrentar tais dilemas implicou, para Kuhn, em revisar seu percurso e reformular alguns de seus passos. Nestes últimos escritos, a questão da incomensurabilidade é ressignificada como um desiderato da especialização do conhecimento. Num paralelo com a árvore da evolução biológica, a especialização é, afirma Kuhn, o florescer de um novo ramo, uma nova espécie, que se diferencia de sua origem. ${ }^{4}$ Vale lembrar que já em 1969, no posfácio à Estrutura das Revoluções Científicas, Kuhn se referia a esse modelo para falar de sua concepção de evolução do conhecimento e do progresso científico. ${ }^{5}$ Mas a isso não se deu muita atenção, e Kuhn continuou sendo vinculado à idéia de incomensurablidade entre diferentes paradigmas científicos e de revolução na mudanças de paradigmas. ${ }^{6}$

Esse modelo da árvore evolutiva explicaria, a seu ver, os vínculos e as especializações de diversas práticas humanas ao longo da história, assim como a progressiva proliferação de novas especialidades dentro da arena científica. No âmbito das sub-especialidades das ciências, por exemplo, é notável a luta de seus praticantes para incrementar o conhecimento específico, tornando mais preciso, mais consistente e mais aplicável o conjunto de crenças que adquiriram durante sua formação.

De acordo com Kuhn, certas características como poder, autoridade e interesse entraram cedo nesse desenvolvimento evolucionário e estão presentes em todas práticas humanas, inclusive na científica. Outras características, no entanto, fariam parte apenas de algumas ramificações, sendo incorporadas somente ao grupo de práticas derivado dessas ramificações. Embora os desenvolvimentos das ciências tenham envolvido diversos galhos e alguns enxertos, as ciências compõem um grupo cujas peculiaridades lhe garantiriam uma

\footnotetext{
4 "Práticas humanas em geral e as científicas em particular têm evolvido em longos períodos de tempo e seus desenvolvimentos formam algo bastante parecido com uma árvore evolutiva”(Kuhn, 2000, 116).

5 "O desenvolvimento científico, tal como o biológico, é um processo unidirecional e irreversível. As teorias cientificas mais recentes são melhores que as mais antigas, no que toca à resolução de quebra-cabeças nos contextos freqüentemente diferentes aos quais são aplicadas. Essa não é uma posição relativista e revela em eu sentido sou um crente convicto do progresso científico"(Kuhn, 1978, 252-3).

${ }^{6}$ Essa insistência em não aceitar a mudança das idéias de Kuhn ao longo do desenvolvimento de sua obra parece ser devido a um certo "didatismo" de seus conceitos desde a primeira edição de A Estrutura das Revoluções Científicas. O fácil entendimento e a possibilidade de uso imediato em várias áreas, por exemplo, do conceito de paradigma impedem, ainda hoje, o seu abandono, embora esse conceito tenha apresentado dificuldades filosóficas (em especial a questão da descontinuidade) que Kuhn tentou resolver abandonando ele próprio o conceito de paradigma.
} 
certa autonomia frente a outras práticas sociais. A noção de verdade, por exemplo, desempenha um papel mais importante no desenvolvimento desse galho das ciências do que no de outras práticas sociais. Sem desconsiderar o papel do interesse e do poder no desenvolvimento cientifico, Kuhn não acredita que estes possam substituir inteiramente as noções de evidência e da razão. Em outros termos, a perspectiva de que fatos não são descobertos mas construídos não significa que eles sejam inteiramente construídos em função das negociações, interesses e forças sociais que interagem no empreendimento científico, pois existem resistências naturais exteriores a tais negociações.

A partir desses seus posicionamentos, podemos perceber que Kuhn, ao responder a esses antigos problemas recolocados pela nova historiografia da ciência, acaba se reaproximando de dois importantes pensadores que o influenciaram de modo decisivo na formação de A Estrutura das Revoluções Científicas : Ludwik Fleck e Ludwig Wittgenstein. Esses autores, cada um a sua maneira, já tinham percebido que para uma compreensão da produção do conhecimento científico deveríamos evitar as "falsas ênfases", isto é, não se deve ignorar as "negociações", mas também não se deve pensar que elas possam substituir não apenas as noções de evidência e de razão, mas sobretudo o modo como a natureza atua.

A aproximação com o pensamento de Fleck (1979) se evidencia quando Kuhn compreende que as revoluções são produtoras de novas divisões nos campos científicos. Para Kuhn, elas não significam o fim de uma espécie, mas o surgimento vigoroso de um novo ramo. As especializações são, pois, como "mutações revolucionárias" do conhecimento. No âmbito da biologia, a unidade da nova espécie é uma variação parcial de certas características genéticas comum na origem, que em determinadas condições ambientais, assegura a auto- perpetuação da espécie isolada do tronco do qual se originara. Determinadas condições ambientais favorecem que ela seja selecionada. No terreno científico, a unidade é a comunidade de especialistas que se intercomunicam, ou seja, a unidade comum está na linguagem, num sentido amplo que envolve o cultivo de determinados termos, protocolos, objetivos, valores.

Ao fazer a analogia da ciência com a biologia, Kuhn se reaproxima da perspectiva trilhada por Fleck. Já em $A$ Estrutura das Revoluções Científicas existiam divergências e semelhanças $^{7}$ entre as direções tomadas pelos dois autores. Parte considerável das divergências talvez se adviesse do fato deles serem provenientes de comunidades de historiadores da ciência com perspectivas bem distintas. As influências de Fleck (darwinismo, escola polonesa de filosofia da medicina, crítica ao positivismo lógico) marcam posições bastante diferentes das defendidas pela comunidade de historiadores da ciência da qual Kuhn é proveniente (A. Koyré, H. Butterfield, A. R. Hall, I. B. Cohen etc.). A tradição em que Kuhn se insere foi marcada pela idéia de que o desenvolvimento da ciência se faz por

\footnotetext{
${ }^{7}$ Essas semelhanças com o livro de Fleck publicado em 1935 são muitas e até mesmo, sob um certo aspecto, chocantes ao leitor habituado a atribuir a Thomas Kuhn muitas das idéias que vê passar pelos seus olhos no livro de Fleck. Para explicar essas semelhanças, Kuhn utiliza o conceito de "serendipismo" ou descoberta acidental. (Fleck, 1979, viii).
} 
descontinuidade, isto é, através de revoluções científicas. ${ }^{8}$ Fleck passa ao largo dessa idéia e entende, a partir de Estilo de Pensamento e Pensamento Coletivo, que o desenvolvimento científico deve ser visto como um processo lento e contínuo em termos darwinistas, assim, a ciência tem uma "evolução" que se processa a partir de uma "mutação" e não uma "revolução" (Fleck, 1979, 26). Mas, ao propor a idéia de "mutações revolucionárias", Kuhn caminha em direção a Fleck, isto é, as divergências tendem a tornar-se convergências. ${ }^{9}$

A obra de Wittgenstein é a outra direção trilhada por Kuhn, sobretudo, na ênfase que Kuhn passa a dar à linguagem. Ao invés da noção de paradigma, Kuhn fala então de comunidade lingüística, ou de um léxico próprio a cada especialidade. Cada novo campo desenvolve com um léxico próprio, sua linguagem, seus departamentos, associações e suas revistas. O compartilhamento de um determinado léxico provê a base para a conduta e a avaliação de suas pesquisas e, ao mesmo tempo, libera o grupo da necessidade de comunicação com outros fora do grupo, mantendo seu isolamento de outros membros de outras especialidades.

É inegável a aproximação dessa abordagem com os conceitos de jogos de linguagem e de gramática presente nas Investigações Filosóficas de Wittgenstein. Ainda que Wittgenstein seja um velho conhecido de Kuhn, não podemos deixar de observar que ele é também um dos grandes inspiradores - juntamente com Durkheim - do "programa forte de sociologia da ciência" de D. Bloor que recebe as críticas de Kuhn. Em uma perspectiva wittgensteiniana, a ciência é um empreendimento que possui suas regras próprias elaboradas a partir dos jogos de linguagem de uma determinada comunidade científica. Esses jogos de linguagem possuem não apenas a dimensão lingüística, mas também o caráter pragmático das ações a ele referidas. Esse conjunto de jogos de linguagem, isto é, práticas, regras, teorias, experimentos etc, a partir dos quais a ciência se desenvolve, poderíamos dizer, compõem a gramática da ciência.

Diferentemente da radicalização das idéias wittgensteinianas feitas pelo "programa forte", a gramática da ciência não é essencialmente uma construção social sem levar em consideração as evidências, a razão e, principalmente, a natureza, pois, para Wittgenstein, se a natureza se comportasse de modo totalmente diferente, isto é, se os fatos fossem outros, nossos jogos de linguagem seriam outros.

Se as coisas se comportassem de modo totalmente diferente do que se comportam de fato - e se não houvesse, por exemplo, expressão característica da dor, do terror, da alegria; se o que é regra tornasse exceção e o que é exceção, regra, ou se as duas coisas tornassem fenômenos de freqüência mais ou menos igual - então nossos jogos de linguagem normais perderiam seu sentido. - O procedimento de colocar um pedaço de queijo sobre uma balança e fixar o preço segundo o que marca o ponteiro

\footnotetext{
${ }^{8}$ Em certo sentido, o trabalho de Kuhn é o ápice dessa tradição na medida em que ele eleva ao extremo a idéia de revolução científica. Não apenas a ciência moderna se constituiu a partir de uma revolução, mas toda ciência é revolucionária. Pressupondo essa concepção é que Kuhn procura explicar "a estrutura das revoluções científicas".

${ }^{9}$ Desde a publicação da Segunda edição de A Estrutura das Revoluções Científicas em 1970 isso se mostra, em especial, com a criação do conceito kuhniano de "matriz disciplinar" para evitar alguns proble mas trazidos pelo conceito de "paradigma".
} 
perderia seu sentido, se acontecesse freqüentemente que tais pedaços, sem causa aparente, crescessem ou diminuíssem repentinamente (Wittgenstein, 1978, 62).

Percebe-se aqui que, para Wittgenstein, embora a linguagem seja uma instituição em que as "negociações" certamente estão presentes, a gramática não está totalmente "descolada" da natureza. A gramática é autônoma, mas não independente.

Entretanto, esse direcionamento de Kuhn rumo à linguagem apresenta algumas divergências com Wittgenstein das quais talvez a principal seja a tentativa de Kuhn em "categorizar" a linguagem. Em outras palavras, Kuhn chega a esboçar uma analogia entre esse léxico próprio (a gramática de Wittgenstein) e as categorias kantinanas ou neokantianas, ainda que as entenda não como eternas, mas como condicionadas histórica e culturalmente, isto é, relativizadas. O léxico denota, portanto, condição de possibilidade, constitutiva do objeto de conhecimento e dos fenômenos naturais. O que faz do conhecimento do mundo algo dependente da percepção humana, mas não só desta. $\mathrm{O}$ léxico, como as categorias kantianas, constitui as possíveis experiências de mundo, mas

quais dessas concebíveis experiências ocorre no mundo real é algo que deve ser apreendido com a experiência cotidiana e com experiências mais sistemáticas e refinadas que caracterizam a prática científica. São ambas duras mestras, firmemente resistentes à promulgação de crenças que não sucedem no mundo que o léxico possibilita (Kuhn, 2000, 245).

Contudo, não há uma língua franca capaz de expressar e transmitir em sua inteireza os conteúdos de um campo para outro. Nesse sentido, vale frisar que uma das conseqüências da especialização é uma limitação da comunicação ${ }^{10}$ e da comunidade de conversação. Retomando uma idéia central de seu artigo "A função do dogma na investigação científica", de 1963, Kuhn observa, nestes últimos escritos, que o estreitamento do campo é um preço necessário para o crescimento do poderio das ferramentas cognitivas. Para quem se preocupa com a unidade do conhecimento, a especialização, com suas linguagens próprias, é um problema. Contudo, conforme Kuhn já havia mostrado no artigo mencionado a pouco, a diversidade, ainda que necessária ao desenvolvimento do conhecimento, é um limite à comunicação e ao desenvolvimento de uma percepção mais sensível a anomalias. A limitação do leque de possíveis companheiros para um frutífero intercurso é a pré-condição essencial para o que é conhecido como progresso, seja no desenvolvimento biológico, seja no desenvolvimento cognitivo.

Embora Kuhn esteja certo em atribuir às categorias uma dimensão histórica e social, em uma perspectiva wittgensteiniana não faz sentido, a partir dos jogos de linguagem, pensar em termos de categorias. Os jogos de linguagem seriam exatamente a tentativa de eliminar as categorias com finalidade de "dissolver" as dicotomias tradicionais ou "falsas ênfases" (como por exemplo, internalismo versus externalismo). A insistência de se manter categorias ainda seria um resquício da filosofia tradicional metafísica. Novamente, parece

\footnotetext{
${ }^{10}$ Esse problema é tratado tanto por Wittgenstein quanto por Fleck, para quem, por exemplo, não existe uma incomensurabilidade total entre os Estilos de Pensamento, mas dificuldades na comunicação entre eles.
} 
que as questões que Kuhn procuram resolver ainda encontram boas possibilidades de solução em suas fontes de influência.

Há, sem dúvidas, muitos outros pontos interessantes a serem explorados nestes últimos escritos de Kuhn que ultrapassam os limites desse artigo. Acreditamos que muitos só serão satisfatoriamente detalhados somente quando sua última obra for publicada. Se Kuhn permanece vago em certos aspectos, há que se lhe conceder também uma franqueza e clareza impar na colocação de questões fundamentais. O delineamento de sua posição no atual debate metodológico da historiografia da ciência revela não só alguns compromissos implícitos em seu trabalho de historiador, como também ajuda-nos a identificar dilemas que permanecem sem compreensão satisfatória aos estudos sobre a ciência. 


\section{REFERÊNCIAS BIBLIOGRÁFICAS}

CARROLL, L. A caça ao turpente. Além Paraíba: Interior Edições, 1984.

BLOOR, D. Knowledge and Social Imagery. Londres: Routledge, 1976.

KUHN, T. The road since structure: philosophical Essays, 1970-1993, with an Autobiographical Interview. Edited by James Conant and John Haugeland. Chicago: Chicago University Press, 2000.

. A Estrutura das Revoluções Científicas. São Paulo: Perspectiva, 1978, $2^{a}$ edição.

. "Foreword". In: FLECK. L. Genesis and Development of a Scientific Fact. Chicago:

Chicago University Press, 1979.

FLECK. L. Genesis and Development of a Scientific Fact. Chicago: Chicago University Press, 1979.

HEILBRON, J. “Eloge: Thomas Samuel Kuhn”. Isis 1998, 89: 505-515.

HORWICH, P. World changes: thomas Kuhn and the nature of science. Cambridge: MIT Press, 1993.

SARDAR, Z. Thomas Kuhn and the science wars. Cambridge, Icons Books:2000.

SHAPIN, S.; SHAFFER, S. Leviathan and the Air-Pump. Princeton: Princeton University Press, 1985

WITTGENSTEIN, L. Investigações Filosóficas. São Paulo: Abril cultural, 1978. 